\title{
On some new or rare spider species from Lesbos, Greece (Araneae: Agelenidae, Amaurobiidae, Corinnidae, Gnaphosidae, Liocranidae)
}

\section{Robert Bosmans}

doi: $10.5431 /$ aramit4003

\begin{abstract}
In this paper, three new spider species are described from the Greek Aegean island Lesbos: Tegenaria maelfaiti sp. nov. (Agelenidae), Amaurobius lesbius sp. nov. (Amaurobiidae) and Agroeca parva sp. nov. (Liocranidae), as well as the unknown male of Arabelia pheidoleicomes Bosselaers, 2009 (Corinnidae). Diagnostic features and notes on ecology and distribution of these species are given. Two new records for the island are provided, such that currently 300 spider species are known from Lesbos.
\end{abstract}

Key words: Agroeca, Amaurobius, Arabelia, description, new species, Tegenaria

The spider fauna of Greece is still poorly known compared to other Mediterranean countries. Recently, BOSMANS \& CHATZAKI (2005) reported 856 species known from Greece. In a study of one relatively small region, the Nestos delta, BUCHHOLZ (2007) added 61 spider species to the Greek fauna. The spiders of the island Lesbos were recently surveyed by a group of Belgian arachnologists during several collecting trips (October 2007, March-April 2008, May-June 2008). This resulted in a catalogue of 292 species, some of them new to science. Among these, VAN KEER \& BOSMANS (2009) described four new dysderid species. The current paper provides the description of three more new species, belonging to the families Agelenidae, Amaurobiidae and Liocranidae and the description of the unknown male of another liocranid genus.

\section{Material and Methods}

The material treated in this paper was collected by members of the Belgian Arachnological Society ARABEL during several trips to Lesbos, as detailed in BOSMANS et al. (2009).

Specimens were examined and illustrated using a Wild M5 stereomicroscope. Further details were studied using an Olympus CH-2 stereoscopic microscope with a drawing tube.

Structures of the left palpus are depicted. All morphological measurements are given in millime-

\footnotetext{
Robert BOSMANS, Terrestrial Ecological Unit, Department of Biology, Ghent University, Ledeganckstraat 35, B-9000 Gent, Belgium; E-Mail: robert.bosmans@Ine.vlaanderen.be
}

tres. Somatic morphology measurements were taken using a scale reticule in the eyepiece of the stereo microscope. Measurements of the legs are taken from the dorsal side. Spines on leg segments are listed in the following order: dorsal-prolateral-retrolateral-proventral-retroventral.

Male palps were detached and transferred to glycerol for examination under the microscope. Female genitalia were excised using sharpened needles and then transferred to clove oil for examination under the microscope. Later, palps and epigynes were returned to $70 \%$ ethanol.

Type material and important reference material is deposited in the Koninklijk Belgisch Instrituut voor Natuurwetenschappen, Brussels, the other material is deposited in the collections of the individuals listed below.

The following abbreviations are used in the text:

AME: anterior median eyes;

CJVK: collection Johan Van Keer;

CHDK: collection Herman De Koninck;

CRB: collection Robert Bosmans;

KBIN: Koninklijk Belgisch Instituut voor Natuurwetenschappen (Brussels);

Legs: Ta: tarsus; Mt: metatarsus; Pa: patella; Fe: femur.

Spines: d: dorsal; v: ventral; pl: prolateral; rl: retrolateral; spines listed between brackets: occurring in pairs or groups at about the same level; *: spines with a terminal position. 


\section{Results}

Family Agelenidae Genus Tegenaria Latreille, 1804

According to BOLZERN et al. (2009), the differences between the genera Tegenaria and Malthonica Simon, 1898 remain unclear. GUSEINOV et al. (2005) distinguished the two genera by the embolus length but BOLZERN et al. (2008) argued that this character is unsuitable for phylogenetic evaluation. Assigning a new species to a correct genus thus becomes difficult without a comprehensive revision of the two genera (BOLZERN et al., 2009). The species described below has a relatively short embolus and is provisionally placed in the genus Tegenaria.

Tegenaria maelfaiti sp. nov. (Figs. 1-5).

Type material. Holotype male, 2 paratype males from Greece, Lesbos, Nomos Mandamados: road Klio-Sykaminia ( $\mathrm{N} 39^{\circ} 22^{\prime} 33^{\prime \prime}$ E $\left.26^{\circ} 10^{\prime} 59^{\prime \prime}\right), 350 \mathrm{~m}$, litter and stones in small Pinus forest, 27.III.2008, R. Bosmans leg.; paratype female from Greece, Lesbos, Nomos Agiasos, Agiasos S. (N 39 $\left.05^{\prime} 53^{\prime \prime} \mathrm{E} 26^{\circ} 21^{\prime} 57^{\prime \prime}\right), 550 \mathrm{~m}$, stones in Castanea forest, 2.IV.2008, L. Baert leg. (KBIN). Deposited in KBIN.

Etymology: The species is dedicated to my good friend and excellent ecologist the late Jean-Pierre Maelfait.

Diagnosis: Males of the species are readily distinguished from other Tegenaria species by the combined characters of the tibial apophyses and the bifid median apophyses. Tegenaria longimana Simon, 1879 from Turkey is a related species, with similar but differently shaped tibial apophysis and distal parts of the median apophysis. Females are recognized by the absence of sclerotisation in the epigyne and the course of the copulatory ducts.

\section{Description}

Measurements (males $n=27$, females $n=4$ ): Male: Total length 3.8-6.2; prosoma 1.59-2.79 long, 1.462.06 wide. Female: Total length 4.8-5.0; prosoma 1.87-1.98 long, 1.34-1.43 wide. Leg measurements as in Table 1.

Colour: Prosoma yellowish brown to brown, with submarginal stripe, touching at level of fovea, and narrow grey margin; chelicerae yellowish brown; sternum grey with median stripe and 3 lateral whitish spots. Legs pale yellowish, $\mathrm{Fe}, \mathrm{Ti}$
Table 1: Tegenaria maelfaiti sp. nov. leg measurements (holotype).

\begin{tabular}{r|c|c|c|c|c} 
& $\mathrm{Fe}$ & $\mathrm{Pt}$ & $\mathrm{Ti}$ & $\mathrm{Mt}$ & $\mathrm{Ta}$ \\
\hline Palp & 1.23 & 0.42 & 0.76 & - & 0.79 \\
\hline I & 3.24 & 0.92 & 3.29 & 3.44 & 1.62 \\
\hline II & 2.85 & 0.78 & 2.31 & 2.97 & 1.37 \\
\hline III & 3.23 & 0.60 & 1.96 & 2.57 & 0.96 \\
\hline IV & 2.96 & 0.76 & 2.72 & 3.52 & 3.51
\end{tabular}

and Mt greyish at ends, Fe with 2 grey annulations, $\mathrm{Ti}$ and Mt with 1 median annulation. Abdomen dorsally greyish black, with anteromedian area and 5-6 chevrons whitish, ventrally whitish with scattered greyish black spots, anastomising in some specimens. Spinnerets whitish, dorsal side of dorsal spinneret and ventral side of ventral spinneret greyish black. Leg spination as in Table 2.

Male palp (Figs. 1-3): Tibia elongated, dorsal apophysis long, with parallel margins and rounded terminally, retrolateral apophysis a large, rounded lobe. Median apophysis bifid, with shorter, pointed anterior tooth and longer, less pointed posterior tooth. Conductor slightly shorter than alveolus, rounded, folded along its entire retrolateral margin, terminal part pointing in posterior direction. Embolus filiform, semi-circular, arising on mesal side of bulbus.

Epigynum and vulva (Figs. 4-5): Epigynal plate slightly protruding over epigastric furrow, posterior margin with two indistinct concavities, with a pair of posteriorly directed teeth but without exterior sclerifications; copulatory ducts wide; spermathecae rounded.

\section{Further material examined}

Agiasos: Oros Olympos (N 39 $9^{\circ} 04^{\prime} 01^{\prime \prime}$ E $\left.26^{\circ} 21^{\prime} 30^{\prime \prime}\right), 800$ $\mathrm{m}, 1$ female, stones in Platanus forest, 2.VI.2008 (CRB); - Kalloni: Anemotia, E. of Moni Voukolon (N 39 $04^{\prime} 00^{\prime \prime} \mathrm{E}$ $\left.26^{\circ} 07^{\prime} 18\right), 400 \mathrm{~m}, 1$ female, stones in grassland, 29.III. 2008 (KBIN); road Anemotia-Skala Kallonis, Karyo (N 39 $133^{\prime 3} 6^{\prime \prime}$ E $\left.26^{\circ} 07^{\prime} 50^{\prime \prime}\right), 100 \mathrm{~m}$, litter and herbs along rivulet, 29.III.2008 (CRB); - Mandamados: road Klio-Sykaminia (N 39 22'33" E 26 $\left.6^{\circ} 10^{\prime} 59^{\prime \prime}\right), 350 \mathrm{~m}, 24$ males, litter and stones in small Pinus forest, 27.III.2008 (CHDK, CJVK, CRB); - Mithymna: road Argenos-Vafios (N 39 $21^{\circ} 06^{\prime \prime}$ E
Table 2: Tegenaria maelfaiti sp. nov. leg spination (holotype).

\begin{tabular}{r|c|c|c|c|c} 
& Fe & Pt & Ti & Mt & Ta \\
\hline I & (dpl)-d-pl & d-d & d & v rl (plrl) & - \\
\hline II & d-d-(plrl) & d-d & d & vpl 2v (plrl) & - \\
\hline III & d-d-(plrl) & d-d & d (plrl) & rl pv (rlplpvrv) & - \\
\hline IV & d-(pl-rl) & d-d & (drl) (pvplrl) (dplrl) & (pvrv) (plrlrv) (plrlpvrv) & -
\end{tabular}




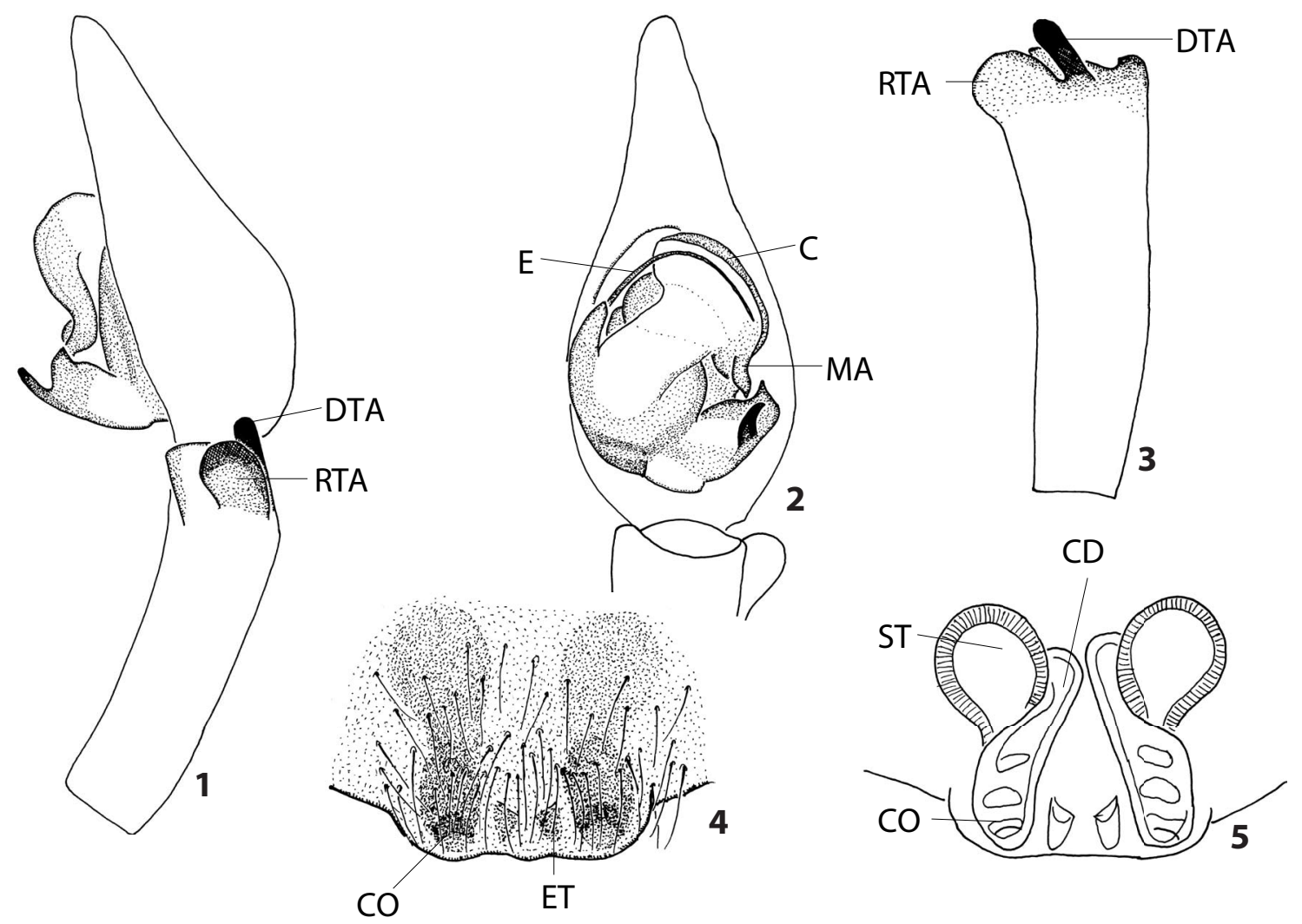

Figures 1-5: Tegenaria maelfaiti sp. nov. 1. Male palp, lateral view; 2. Idem, ventral view; 3. Palpal tibia, dorsal view; 4 . Epigyne, ventral view; 5 . Vulva, ventral view. $C=$ conductor; $C D=$ copulatory duct; $C O=$ copulatory opening; $D T A=$ dorsal tibial apophysis; $E=$ embolus; $\mathrm{ET}=$ epigynal tooth; $\mathrm{MA}=$ median apophysis; $\mathrm{RTA}=$ retrolateral tibial apophysis; $\mathrm{ST}$ = spermatheca.

$\left.26^{\circ} 14^{\prime} 29^{\prime \prime}\right), 320 \mathrm{~m}, 3$ males, stony grassland and shrubs, 28.III.2008 (CHDK, CJVK, CRB).

Ecology: Males were collected in March and April, females in March, April and June. It was mainly found in forest (pine, chestnut and plane forests), but also in shrubs and olive groves and along rivulets.

Distribution: Only known from Lesbos. As Tegenaria species tend towards small distribution areas, this species is possibly endemic to the island.

\section{Family Amaurobiidae}

\section{Genus Amaurobius C. L. Koch}

The genus Amaurobius currently includes 67 species (PlaTNICK 2010) and has a mainly Holarctic distribution. In Greece, it has been thoroughly studied by THALER \& KNOFLACH (1991, 1993, 1995, 1998, 2002) and WundERLiCH (1995). Thirteen Amaurobius species have been found in Greece (BOSMANS \& CHATZAKI 2005). A. candia Thaler \& Knoflach, 2002, A. cretaensis Wunderlich, 1995 and $A$. geminus Thaler \& Knoflach, 2002 are endemics for Crete, A. phaeacus Thaler \& Knoflach, 1998 is an endemic for Kerkyra, A. deelemanae Thaler \& Knoflach, 1995 occurs on Crete, the Dodekanisa and Kyklades and
A. ausobskyi Thaler \& Knoflach, A. longipes Thaler \& Knoflach, 1995, A. ossa Thaler \& Knoflach, 1993, $A$. paon Thaler \& Knoflach, 1993 and $A$. pelops Thaler \& Knoflach, 1991 are endemics occurring in continental Greece. Amaurobius pallidus L. Koch, 1868 and $A$. strandi Charitonov, 1937 have an eastern Mediterranean distribution and $A$. erberi (Keyserling, 1863) has a circummediterranean distribution. From the Eastern Aegean islands (to which Lesbos belongs) only Amaurobius scopolii Thorell, 1871 has been cited from Chios (STRAND 1917) but this is most probably a misidentification. It is thus not surprising to discover another new Amaurobius species on one of the Aegean Islands. 
Amaurobius lesbius sp. nov. (Figs. 6-10)

Type material: Holotype male, 1 paratype male two paratype females from Greece, Lesbos, Nomos Kalloni, Skalochori (N 39 $15^{\prime} 59^{\prime \prime}$ E26 $6^{\circ}$ 05'30"), $300 \mathrm{~m}$, litter in Quercus forest, 2.X.2007, R. Bosmans \& J. Van Keer leg. Deposited in KBIN.

Etymology: The species is named after the island of Lesbos.

Diagnosis: Amaurobius lesbius n. sp. is closely related to the larger $A$. erberi (Keyserling), also occurring on Lesbos. Males differ by the reduction of an intermediate apophysis in the palpal tibia, and the presence of a strongly protruding, rectangular tegular process. Females differ by the closely set spermathecae, separated by less than $1 / 4$ their diameter in the new species and by their diameter in $A$. erberi.

\section{Description}

Colour: Prosoma yellowish brown, sometimes with greyish striae, thoracic part paler; chelicerae dark orange brown. Legs yellowish brown. Abdomen in males dark grey to black with anteromedian pale stripe and some subterminal, pale grey chevrons, venter pale to dark grey, in females dorsally pale grey with dark grey pattern.

Measurements (males: $n=6$; females: $n=8$ ): Male: Total length 3.6-4.6; prosoma 1.81-2.24 long, 1.211.56 wide. Female: Total length 4.8-6.8; prosoma 1.99-2.26 long, 1.18-1.54 wide. Leg measurements as in Table 3, leg spination as in Table 4.

Male palp (Figs. 6-8): Tibia with small, curved dorsal and larger blunt retrolateral apophyses, the former with a tooth at its base, intermediate apophysis reduced to a short crest. Tegular process strongly protruding, nearly rectangular. Tegular apophysis elongated, terminally hooked and embolus short and bent.

Epigyne and vulva (Figs. 9-10): With reversed tra-

Table 3: Amaurobius lesbius sp. nov., leg measurements (holotype).

\begin{tabular}{r|c|c|c|c|c} 
& $\mathrm{Fe}$ & $\mathrm{Pt}$ & $\mathrm{Ti}$ & $\mathrm{Mt}$ & $\mathrm{Ta}$ \\
\hline Palp & 0.72 & 0.26 & 0.34 & - & 0.39 \\
\hline I & 1.51 & 0.76 & 1.36 & 1.54 & 0.91 \\
\hline II & 1.42 & 0.74 & 1.14 & 1.08 & 0.89 \\
\hline III & 1.31 & 0.75 & 0.99 & 1.29 & 0.77 \\
\hline IV & 2.02 & 0.79 & 1.82 & 2.28 & 1.12
\end{tabular}
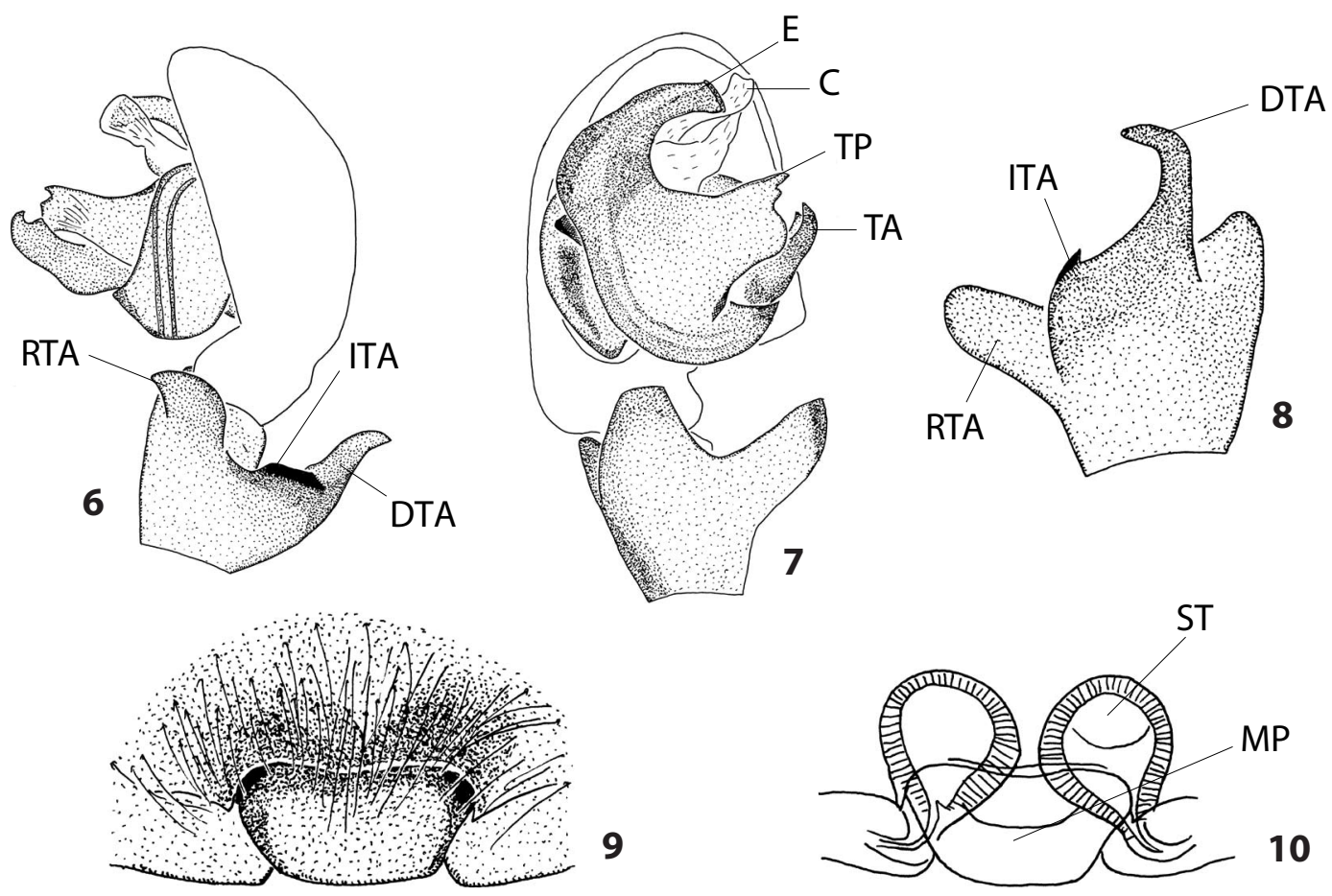

Figures 6-10: Amaurobius lesbius sp. nov. 6. Male palp, lateral view; 7. Idem, ventral view; 8. Palpal tibia, dorsal view; 9 . Epigyne, ventral view; 10. Vulva, ventral view. $C=$ conductor; DTA $=$ dorsal tibial apophysis; $E=$ embolus; ITA = intermediate tibial apophysis; $\mathrm{MP}=$ median plate; $\mathrm{RTA}=$ retrolateral tibial apophysis; $\mathrm{ST}=$ spermatheca; $\mathrm{TA}=$ tegular apophysis; $\mathrm{TP}=$ tegular process . 
Table 4: Amaurobius lesbius sp. nov., leg spination (holotype).

\begin{tabular}{r|c|c|c|c|c} 
& $\mathrm{Fe}$ & $\mathrm{Pt}$ & $\mathrm{Ti}$ & $\mathrm{Mt}$ & $\mathrm{Ta}$ \\
\hline $\mathrm{I}$ & $\mathrm{pl}$ & - & 3pl 2rl 3pv 3rv & 2pl 2rl 3pv 3rv pdrd* & - \\
\hline $\mathrm{II}$ & $\mathrm{pl}$ & - & 3pl 2rl 3pv 3rv & 3pl 2rl pv 2rv pdrd* & - \\
\hline III & (pd rd) & - & 3pl 3pv rv rl & 2pl pv 3rv pd rd* & - \\
\hline IV & $\mathrm{rd}$ & - & pv 3rv rl & rl pv 3rv pd pv* & -
\end{tabular}

pezoid plate. Spermathecae closely set, separated by less than $1 / 4$ their diameter, basal part covered by epigynal plate.

\section{Further material examined}

Agiasos: Agiasos S. (N 39 05'53” E 262'ㄱ'), 550 m, 5 males, pitfalls in Castanea forest, X.2007-IV.2008 (CJVK); -
Mandamados: road Klio-Sykaminia (N 39 22'33” E $\left.26^{\circ} 10^{\prime} 59^{\prime \prime}\right), 350 \mathrm{~m}$, stones in small Pinus forest, 1 subadult male 1 female, 6.X.2007, 6 females, 27.III.2008 (CHDK, CJVK, CRB).

Ecology: All specimens were captured in Castanea, Pinus and Quercus forests. Males were only collected in winter, females in winter and spring.

Distribution: At the moment, the species is only known from Lesbos, but as Amaurobius species generally have large distribution areas, it may occur on other East Aegean Islands as well.

\section{Family Liocranidae}

\section{Genus Agroeca C. L. Koch}

The genus Agroeca currently includes 25 species and has a Holarctic distribution (PLATNICK 2010). In Greece, only Agroeca cuprea Menge, 1873 has been previously reported (BOSMANS \& CHATZAKI 2005). A new species is described below.

\section{Agroeca parva sp. nov.}

(Figs. 11-14)

Type material: Holotype male, 2 male paratypes 1 female paratype from Greece, Lesbos, Polichnitos, Aghios Pavlos E. (N 39 07’38” E 26 14'03”), 10 m, pitfalls in Juncus marsh, 11.X.2007, R. Bosmans leg. Deposited in KBIN.

Etymology: The name refers to the small size of the new species.

Diagnosis: Agroeca parva sp. nov. is recognised by its small size and its contrasting colour. The male palp and female epigyne suggest the species is closely related to Agroeca annulipes Simon, 1878 and A. maghrebensis Bosmans, 1999, both from the western Mediterranean. Males differ by the truncate palpal tibial apophysis, more pointed in the species from the Maghreb, females by the concave lateral margins of the epigynal depression, straight in the species from the Maghreb.

\section{Description}

Colour: Prosoma yellowish brown with narrow margin and submedian stripe greyish black. Abdomen grey black, median denticulate stripe grey brown, venter yellowish brown with few grey black spots in posterior half. Legs yellowish brown, femora with 2 broad grey annulations, patellae I-III with basal half grey.

Measurements (males: $\mathrm{n}=3$, females $\mathrm{n}=6$ ): Male: Total length 3.6-3.8; prosoma 1.84-2.12 long, 1.441.71 wide. Female: Total length 4.1-4.5; prosoma 1.83-2.16 long, 1.51-1.64 wide. Leg measurements as in Table 5, leg spination as in Table 6 .
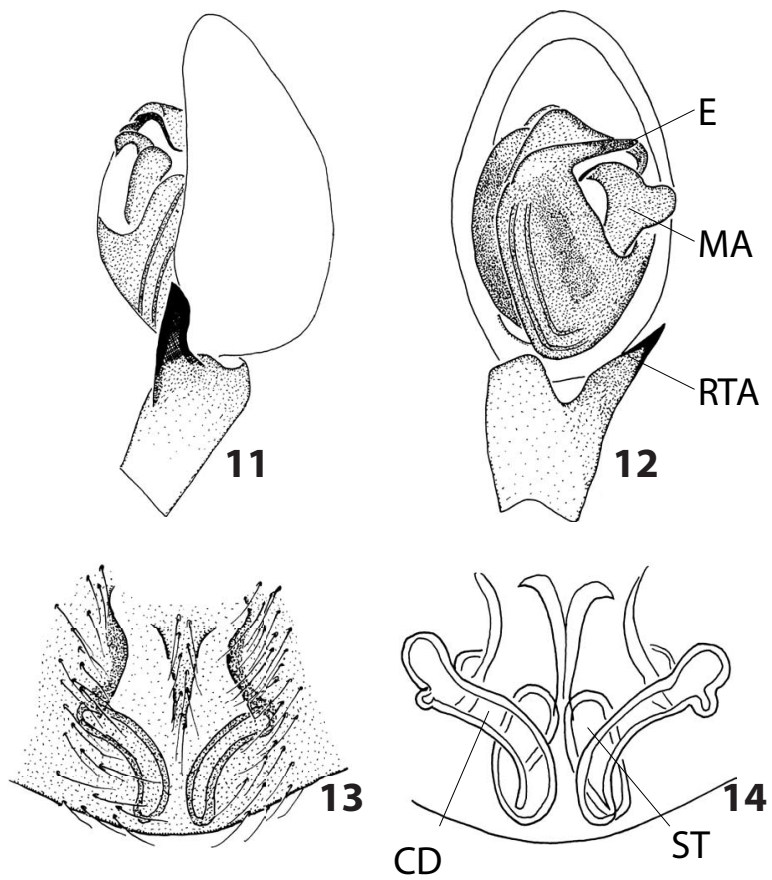

Figures 11-14: Agroeca parva sp. nov. 11. Male palp, lateral view; 12. Idem, ventral view; 13. Epigyne, ventral view; 14 . Vulva, ventral view. $\mathrm{CD}=$ copulatory duct; $\mathrm{E}=$ embolus; $\mathrm{MA}=$ Median apohysis; $\mathrm{RTA}=$ retrolateral tibial apophysis; $\mathrm{ST}=$ spermatheca. 
Table 5: Agroeca parva sp. nov. leg measurements (holotype).

\begin{tabular}{|r|c|c|c|c|c|}
\cline { 2 - 6 } \multicolumn{1}{c|}{} & Fe & Pt & Ti & Mt & Ta \\
\hline Palp & 0.72 & 0.26 & 0.34 & - & 0.39 \\
\hline I & 1.51 & 0.76 & 1.36 & 1.54 & 0.91 \\
\hline II & 1.42 & 0.74 & 1.14 & 1.08 & 0.89 \\
\hline III & 1.31 & 0.75 & 0.99 & 1.29 & 0.77 \\
\hline IV & 2.02 & 0.79 & 1.82 & 2.28 & 1.12 \\
\hline
\end{tabular}

Table 6: Agroeca parva sp. nov. leg spination (holotype).

\begin{tabular}{|c|c|c|c|c|c|}
\cline { 2 - 6 } \multicolumn{1}{c|}{} & Fe & Pt & Ti & Mt & Ta \\
\hline I & $2 \mathrm{~d} 1 \mathrm{pl}$ & - & 2 (pv rv) & 3 (pv rv) & - \\
\hline II & $2 \mathrm{~d} 1 \mathrm{pl}$ & - & 2 (pv rv) & 3 (pv rv) & - \\
\hline III & $2 \mathrm{~d} 1 \mathrm{pl}$ & 1d & 2pl 3pv 3rv 2rl & 3 pl 3pv 3rv 3rl & - \\
\hline IV & $2 \mathrm{~d} 1 \mathrm{pl}$ & 1d & 3pl 3pv 3pl 3rl & 3 pl 3pv 3rv 3rl & - \\
\hline
\end{tabular}

Male palp (Figs. 11, 12): Tibia with thick, straight apophysis, terminally truncate at dorsal margin. Median apophysis reversed L-shaped, with distinct anterior concavity and terminally pointed. Embolus gradually narrowing terminally curved towards the median apophysis.
Epigyne and vulva (Figs. 13-14): With large median depression, concave lateral margins and a posteriorly narrowing median septum.

\section{Further material examined}

Agiasos: Megali Limni W., Steni Klidi, (N 3906'47” E $\left.26^{\circ} 18^{\prime} 30^{\prime \prime}\right), 400 \mathrm{~m}, 2$ females, pitfalls in Pinus forest, 3.IV.2008 (CJVK, CRB); - Kalloni: Skala Kalloni (N $39^{\circ} 12^{\prime} 28^{\prime \prime}$ E $\left.26^{\circ} 12^{\prime} 01^{\prime \prime}\right), 10 \mathrm{~m}, 1$ female, litter in vegetable garden of hotel, 6.X .2007 (CRB); - Polichnitos: Polichnitos salt works (N 39 06'37” E $\left.26^{\circ} 10^{\prime} 50^{\prime \prime}\right), 5 \mathrm{~m}$, stones in Salicornia salt marsh, 2 females, 31.III.2008 (CRB); Vatera (N $39^{\circ} 01^{\prime} 00^{\prime \prime}$ E $\left.26^{\circ} 13^{\prime} 59^{\prime \prime}\right), 30 \mathrm{~m}, 1$ male, litter in garden of hotel, 9.X.2007 (CRB).

Ecology: Males of this species were only collected in October, females in October and March. It was found in salt marshes, pine forests and even in a vegetable garden, so there seem to be no particular habitat preferences.

Distribution: Currently, only known from Lesbos, but as all other Agroeca species have large distribution areas, it probably occurs in a much wider area.

\section{Family Corinnidae}

\section{Genus Arabelia Bosselaers, 2009}

The genus Arabelia was only recently described and includes a single species from the East Mediterranean region. The male is described here for the first time.

\section{Arabelia pheidoleicomes Bosselaers, 2009}

(Figs. 15-16)

Arabelia pheidoleicomes Bosselaers, 2009: 51, Figs. 2K, 7 A-G, 8H, 9 (descr. female).

\section{Remark}

The female of this species was recently described by BOSSELAERS (2009), based on material from Rhodes and Lesbos. Later, the corresponding male appeared to be present in the material from Lesbos as well and it is described here for the first time. Somatic morphology is the same as in the female, except as indicated below.

\section{Diagnosis}

The male of this species is recognised by the short, pointed tibial apophysis and the small sperm duct tooth. For a description of the female, see BOSSELAERS (2009).

\section{Description of the unknown male}

Colour: As in female, but femora and patella of legs I-II somewhat infuscate, contrasting with paler remaining segments.

Measurements (1 male): Total length 3.5; prosoma 1.36 long, 1.21 wide. Leg measurements as in Table 7, leg spination as in Tab. 8.

Male palp (Figs. 15-16): Tibia with small, pointed retrolateral apophysis. Bulbus ovoid, without apophyses, only with small, anterolateral sperm duct tooth.

\section{Material examined}

Agiasos: Agiasos NW, Voula (N 3906’26” E 26²1'14”), 350 m, 1 male, 1.IV.2008, dense Pinus forest along rivulet, 1.IV.2008, L. Baert leg.; deposited in KBIN.

\section{Distribution}

Greece (Rhodes, Lesbos) and Cyprus.

\section{Ecology}

Females were always collected together with ants, the only male collected was found in a termite nest. 

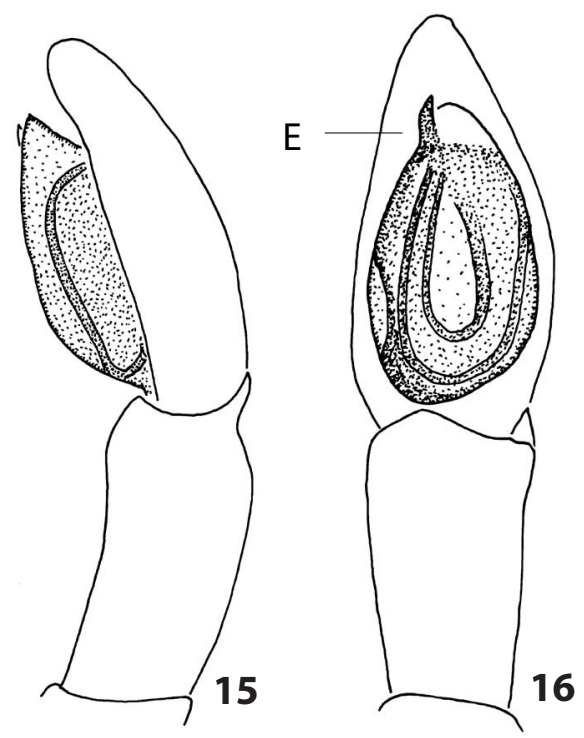

Figures 15-16: Arabelia pheidoleicomes Bosselaers, 2009. 15. Male palp, lateral view; 16 . Idem, ventral view. $E=$ embolus.

\section{New spider records from Lesbos}

Fam. Gnaphosidae

Drassodes lacertosus O. P.-Cambridge, 1872

Identification

Levy, 2004: 6, f. 13-19.

Material examined

Mithymna: Mithymna (N 39²2’02” E 2610'30”), 10 m, 1 male in pool of hotel, 28.V.2009, A. Decae leg. (CRB).

Distribution: The species is known from Turkey, Israel, Syria and Russia (PLATNICK 2010) and is new to Greece. The present record is the most western one.

\section{Trachyzelotes barbatus (L. Koch, 1866) Identfication}

Chatzaki, Thaler \& Mylonas, 2003: 53, f. 20-21, 26-27.

\section{Material examined}

Mithymna: Mithymna (N 39²2'02” E 2610'30”), 10 m, 4 males 1 female in pool of hotel, 28.V.2009, A. Decae leg. (CRB).

Distribution: Mediterranean to Central Asia, USA. New to Lesbos, but previously recorded in continental Greece and Crete (CHATZAKI et al. 2003).

\section{Discussion}

In their catalogue of the spiders of Lesbos, BOSMANS et al. (2009) list 298 species, some of them previously undescribed. Three Harpactea species and one Stalag- tia species were described in VAN KEER \& BOSMANS (2009), one Zodarion species in BOSMANS (2009) and three more species are described in the present paper. Additional species belonging to the spider family Linyphiidae will be described in a further paper.

Finally, some species were discovered that remain unidentified to species level, for different reasons. Sometimes, only one sex was captured, sometimes the genus is in need of revision or the systematic position is unclear. Further investigations are necessary to solve these problems. The description of these species can only be carried out after revisions of the relevant genera or after the discovery of the corresponding sex.

\section{Acknowledgements}

I wish to thank my friends and colleagues Léon Baert, Jan Bosselaers, Herman De Koninck, Jean-Pierre and Lutgarde Maelfait and Johan Van Keer for joining me on Lesbos and making this journey such a pleasant event and also allowing me to examine their material. Arthur Decae is thanked for making available his material collected in Lesbos. The English of the final draft was kindly checked by Anthony Russell-Smith.

\section{References}

Bolzern A., A. HÄNGGi \& D. BuRCKHARDT (2008): Funnel web spiders from Sardinia: taxonomical notes on some Tegenaria and Malthonica spp. (Araneae: Agelenidae). - Revue suisse de Zoologie 115: 759-778

BolZERn A., L. CRESPO \& P. CARDOSO (2009): Two new Tegenaria species (Araneae: Agelenidae) from Portugal. - Zootaxa 2068: 47-58

Bosmans R. (2009): Revision of the genus Zodarion Walckenaer, 1833, part III. South East Europe and Turkey (Araneae: Zodariidae). - Contributions to Natural History 12 (Konrad Thaler Memorial Volume): 211-296

Bosmans R. \& M. CHATZAKI (2005): A catalogue of the spiders of Greece. A critical review of all spiders species cited from Greece with their localities. - Nieuwsbrief van de Belgische arachnologische Vereniging 20 (2, suppl.): $1-124$

BOSMANS R., L. BAERT, J. BOSSELAERS, H. DE KONINCK, J.-P. Maelfait \& J. VAn KeER (2009): Spiders of Lesbos (Greece). A catalogue with all currently known spider reports from the Eastern Aegean Island of Lesbos. - Nieuwsbrief van de Belgische arachnologische Vereniging 24 (suppl.): 1-71

Bosselaers J. (2009): Studies in Liocranidae (Araneae): redescriptions and transfers in Apostenus Westring and Brachyanillus Simon, as well as description of a new genus. - Zootaxa 2141: 37-55 
BuchHolz S. (2007): A first contribution to the Arachnofauna (Arachnida: Araneae) of the Nestos Delta (NE Greece). - Acta Zoologica Bulgarica 59: 241-252

Chatzaki M., K. Thaler \& M. Mylonas (2003): Ground spiders (Gnaphosidae; Araneidae) of Crete (Greece). Taxonomy and distribution. III. Zelotes and allied genera. - Revue suisse de Zoologie 110: 45-89

GuSEINOV E.F., Y.M. MARUSIK \& S. KOPONEN (2005): Spiders (Arachnida: Aranei) of Azerbaijan 5. Faunistic review of the funnel-web spiders (Agelenidae) with the description of a new genus and species. - Arthropoda Selecta 14: 153-177

LEVY G. (2004): Spiders of the genera Drassodes and Haplodrassus (Araneae, Gnaphosidae) from Israel. - Israel Journal of Zoology 50: 1-37 - doi: 10.1560/RUQP20ML-VDBA-3GKX.

PLATNICK N. (2010): The world spider catalog, version 10.5 American Museum of Natural History. - Internet: http://research.amnh.org/entomology/spiders/catalog

STRAND E. (1917): Arachnologica varia XIX-XX. - Archiv für Naturgeschichte 82: 158-167

Thaler K. \& B. KNOFlaCH (1991): Eine neue Amaurobius-Art aus Griechenland (Arachnida: Araneae, Amaurobiidae). - Mitteilungen der schweizerischen entomologischen Gesellschaft 64: 265-268
THALER K. \& B. KNOFLACH (1993): Two new Amaurobius species (Araneae: Amaurobiidae) from Greece. - Bulletin of the British arachnological Society 9: 132-136

ThaleR K. \& B. KNOFLACH (1995): Über Vorkommen und Verbreitung von Amaurobius-Arten in Peloponnes und Ägäis (Araneida: Amaurobiidae). - Revue suisse de Zoologie 102: 41-60

THALER K. \& B. KNOFLACH (1998): Two new species and new records of the genus Amaurobius (Araneae, Amaurobiidae) from Greece. In: SELDEN P.A. (Ed.): Proceedings of the 17th European Colloquium of Arachnology, Edinburgh 1997, Edinburgh. pp. 107-114

Thaler K. \& B. Knoflach (2002): A superspecies in the genus Amaurobius on Crete, and additional records from Greece (Araneae: Amaurobiidae). In:ToFT S. \& N. SCHARFF (Eds): European Arachnology 2000. Proceedings of the 19th European Colloquium of Arachnology, Aarhus. Univ. Press, Aarhus. pp. 337-344

VAN KeER J. \& R. Bosmans (2009): On some new Harpactea and Stalagtia species from Lesbos, Greece (Araneae: Dysderidae).- Acta Zoologica Bulgarica 61: 2009: 277-285

WUNDERLICH J. (1995): Beschreibung einer bisher unbekannten Art der Gattung Amaurobius C. L. Koch 1837 von Kreta (Arachnida: Araneae: Amaurobiidae). - Beiträge zur Araneologie 4: 729-730 